\title{
Efeitos de épocas de aplicação de nitrogênio no rendimento de grãos do milho(1)
}

\author{
Paulo Sérgio Lima e Silva(2) e Paulo Igor Barbosa e Silva(2)
}

\begin{abstract}
Resumo - Um estudo foi realizado em dois anos, com irrigação por aspersão, para avaliar os efeitos da época de aplicação de $120 \mathrm{~kg} / \mathrm{ha}$ de N (sulfato de amônio) no rendimento de grãos do milho. Utilizouse o delineamento de blocos ao acaso, com cinco repetições e os seguintes tratamentos: aplicação de todo o N por ocasião do plantio (1-0-0), em cobertura, aos 25 (0-1-0) e aos 45 (0-0-1) dias após o plantio, e aplicação do $\mathrm{N}$ de forma parcelada $(0-1 / 3-2 / 3,1 / 3-0-2 / 3,1 / 3-2 / 3-0,0-1 / 2-1 / 2,1 / 2-0-1 / 2$, $1 / 2-1 / 2-0,0-2 / 3-1 / 3,2 / 3-0-1 / 3,2 / 3-1 / 3-0$ e 1/3-1/3-1/3). O efeito de tratamentos foi independente do efeito de anos. O maior rendimento de grãos (4.960 kg/ha) foi obtido com o tratamento 0-1/3-2/3, mas todos os demais tratamentos propiciaram rendimentos comparáveis, exceto os tratamentos 1-0-0, 1/3-2/3-0 e 2/3-1/3-0, que apresentaram os menores rendimentos.
\end{abstract}

Termos para indexação: Zea mays, adubos.

\section{Effects of timing of nitrogen application on grain yield of maize}

\begin{abstract}
A two-year study was carried out at Mossoró county, Brazil, with sprinkler irrigation, in order to evaluate the effects of timing of application of $120 \mathrm{~kg} / \mathrm{ha}$ of $\mathrm{N}$ (ammonium sulphate) on grain yield of maize. The randomized blocks design with five replications and the following treatments were utilized: whole application of preplanting (1-0-0), side dressed at 25 (0-1-0) or at 45 (0-0-1) days after planting and split applications $(0-1 / 3-2 / 3,1 / 3-0-2 / 3,1 / 3-2 / 3-0,0-1 / 2-1 / 2,1 / 2-0-1 / 2,1 / 2-1 / 2-0$, $0-2 / 3-1 / 3,2 / 3-0-1 / 3,2 / 3-1 / 3-0$ and $1 / 3-1 / 3-1 / 3)$. The effect of treatments was independent of the effects of the years. The highest grain yield $(4,960 \mathrm{~kg} / \mathrm{ha})$ was obtained with $0-1 / 3-2 / 3$ treatment, but the other treatments propitiated similar grain yields, except the $1-0-0,1 / 3-2 / 3-0$ and $2 / 3-1 / 3-0$ treatments that showed the lowest grain yields.
\end{abstract}

Index terms: Zea mays, fertilizers.

\section{Introdução}

O milho (Zea mays L.) é uma das culturas mais importantes do Rio Grande do Norte, onde era cultivado, poucos anos atrás, principalmente como cultura de subsistência. Entretanto, vários fatores têm feito com que recentemente o milho seja explorado comercialmente, inclusive por grandes empresas agrícolas, em rotação cultural. Dentre tais fatores, a expansão da agricultura irrigada, graças ao apoio dos governos estadual e federal à irrigação, é o mais importante. Paralelamente à ampliação da área irrigada, tem ocorrido o estabelecimento de granjas, aumentando, com isso, a demanda por grãos na região.

\footnotetext{
(1) Aceito para publicação em 12 de dezembro de 2001.

(2) Escola Superior de Agricultura de Mossoró, Caixa Postal 137, CEP 59625-900 Mossoró, RN. E-mail: paulosergio@esam.br
}

A adubação do milho com $\mathrm{N}$ é importante, porque ele é um dos principais nutrientes que favorecem a elevação dos rendimentos de grãos desta cultura (Cardwell, 1982), apesar de seus efeitos dependerem de fatores genotípicos (Carlone \& Russell, 1987) e ambientais (Bondavalli et al., 1970).

Novais et al. (1974), Fox et al. (1986) e Melgar et al. (1991) demonstraram que o parcelamento da adubação nitrogenada proporciona rendimentos de grãos de milho superiores aos obtidos com a aplicação do $\mathrm{N}$ de uma só vez, especialmente quando esta aplicação total é feita em determinadas épocas. Isto é, em alguns casos, a aplicação do $\mathrm{N}$ de uma só vez é equivalente à aplicação parcelada, dependendo da época em que a aplicação total é feita (Novais et al., 1974). Os efeitos do parcelamento do $\mathrm{N}$ dependem das épocas de sua aplicação (Ahmed, 1989; Esechie et al., 1995) e da quantidade que é aplicada em cada época (Bair et al., 1990), dentre outros fatores. 
Alguns autores não têm encontrado vantagem na aplicação parcelada do N para aumentar o rendimento de grãos do milho (Reeves et al., 1993) ou de forragem (Zizka \& Isfan, 1993; Melo et al., 1999).

O objetivo deste trabalho foi estudar os efeitos de épocas de aplicação de nitrogênio no rendimento de grãos de milho.

\section{Material e Métodos}

Dois experimentos foram realizados, na Fazenda Experimental "Rafael Fernandes", da Escola Superior de Agricultura de Mossoró (Esam), em Mossoró, RN. O primeiro experimento foi realizado durante o período de julho a outubro de 1992, e o segundo, de agosto a novembro de 1993. Na Tabela 1 são apresentados dados climáticos medidos durante os períodos experimentais.

$\mathrm{O}$ primeiro experimento foi realizado num Argissolo Vermelho-Amarelo (PVA), cuja análise química $(0-20 \mathrm{~cm})$ revelou: $\mathrm{pH}$ (em água), 6,$4 ; \mathrm{P}, 18 \mathrm{mg} / \mathrm{kg}$; $\mathrm{K}^{+}, 0,11 \mathrm{cmol}_{\mathrm{c}} / \mathrm{dm}^{3} ; \mathrm{Ca}^{2+}, 1,6 \mathrm{cmol}_{\mathrm{c}} / \mathrm{dm}^{3} ; \mathrm{Mg}^{2+}$, $0,8 \mathrm{cmol}_{\mathrm{C}} / \mathrm{dm}^{3} ; \mathrm{Al}^{3+}, 0,0 \mathrm{cmol}_{\mathrm{c}} / \mathrm{dm}^{3} ; \mathrm{Na}^{+}, 0,02 \mathrm{cmol}_{\mathrm{c}} / \mathrm{dm}^{3}$. $\mathrm{O}$ solo foi preparado mediante duas gradagens, e adubado manualmente, no sulco de semeadura, com $60 \mathrm{~kg} \mathrm{de} \mathrm{P}_{2} \mathrm{O}_{5}$ (superfosfato simples) e $30 \mathrm{~kg}$ de $\mathrm{K}_{2} \mathrm{O}$ (cloreto de potássio), por hectare por ocasião da semeadura. Os tratamentos consistiram na aplicação de todo $\mathrm{o} N$ por ocasião do plantio (1-0-0), em cobertura aos 25 (0-1-0) e aos 45 (0-0-1) dias após o plantio e aplicação do $\mathrm{N}$ de forma parcelada $(0-1 / 3-2 / 3,1 / 3-0-2 / 3,1 / 3-2 / 3-0,0-1 / 2-1 / 2,1 / 2-0-1 / 2$, $1 / 2-1 / 2-0,0-2 / 3-1 / 3,2 / 3-0-1 / 3,2 / 3-1 / 3-0$ e $1 / 3-1 / 3-1 / 3)$. Nas adubações em cobertura, realizadas aos 25 ou 45 dias após o plantio, o $\mathrm{N}$ foi colocado em filete contínuo, distante cerca de $10 \mathrm{~cm}$ de cada fileira de plantas. A única exceção foi o tratamento que recebeu toda a dose de $\mathrm{N}$ (120 kg/ha) por ocasião da semeadura cuja aplicação foi feita no sulco.

O sistema de irrigação utilizado foi o de aspersão. A lâmina líquida requerida para o milho $(5,6 \mathrm{~mm})$ foi calculada considerando-se ser de $0,40 \mathrm{~m}$ a profundidade efetiva do sistema radicular. $\mathrm{O}$ momento de irrigar teve por base a água retida no solo à tensão de $0,04 \mathrm{MPa}$. O turno de rega foi de um dia. As irrigações foram iniciadas após o plantio e suspensas dez dias antes da colheita.

Utilizou-se a variedade de polinização-livre Centralmex, que foi semeada em sete de julho de 1992. O delineamento experimental usado foi o de blocos ao acaso, com quatro repetições. As parcelas ficaram constituídas por três fileiras com $6,0 \mathrm{~m}$ de comprimento. Considerou-se como área útil, a ocupada pelos $5,2 \mathrm{~m}$ centrais da fileira central de cada parcela. Entre fileiras, usou-se o espaçamento de $1,0 \mathrm{~m}$, ficando as covas de uma mesma fileira espaçadas por $0,4 \mathrm{~m}$ (duas plantas/cova), ou seja, $50 \mathrm{mil} \mathrm{plantas} / \mathrm{ha}$.

O controle de plantas daninhas foi feito por meio de capinas, e o controle de pragas (Spodoptera frugiperda Smith) foi feito com duas pulverizações de deltamethrin ( $300 \mathrm{~mL} / \mathrm{ha}$ ), sete e 24 dias após o plantio.

A colheita foi realizada 110 dias após o plantio. Foram avaliadas as seguintes características: altura da planta e de inserção da espiga (em dez plantas tomadas ao acaso na área útil de cada parcela), número de ramificações do pendão (nos pendões retirados das mesmas plantas usadas para mensuração das alturas da planta e de inserção da espiga), rendimento de grãos e componentes do rendimento de grãos. Como altura da planta, considerou-se a distância do nível do solo ao ponto de inserção da lâmina foliar mais alta (a chamada folha-bandeira). Como altura de inserção da espiga, considerou-se a distância do nível do

Tabela 1. Médias mensais da temperatura e da umidade relativa do ar e totais mensais de precipitação e insolação, ocorridos em Mossoró, RN, durante os períodos de julho-setembro de 1992 e agosto-novembro de $1993^{(1)}$.

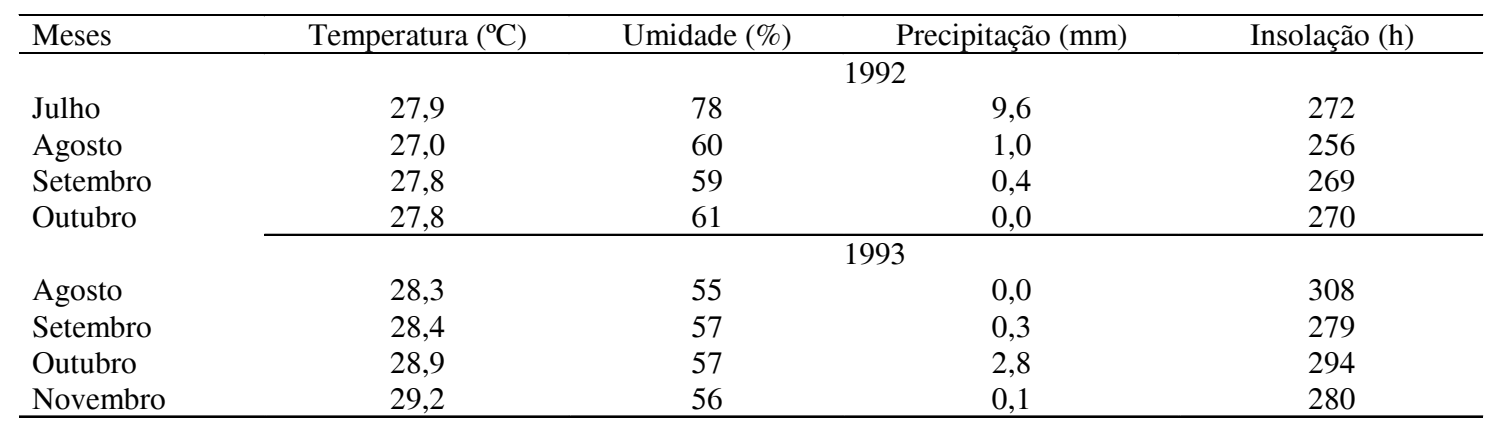

${ }^{(1)}$ Dados coletados em estação meteorológica distante $20 \mathrm{~km}$, aproximadamente, da área experimental. 
solo ao ponto de inserção da espiga mais alta. $\mathrm{O}$ rendimento de grãos foi corrigido para um teor de umidade de $15,5 \%$. O número de espigas/ha foi estimado a partir do número de espigas colhidas em toda a área útil. O número de grãos/ espiga foi estimado em dez espigas tomadas ao acaso entre as espigas da área útil. A estimativa do peso de 100 grãos foi feita em cinco amostras.

As operações realizadas no segundo experimento foram as mesmas do primeiro. Embora realizado em outro local, o solo do segundo experimento era do mesmo tipo do solo do primeiro experimento. Os resultados de sua análise química (0-20) foram: $\mathrm{pH}$ (em água), 7,5; $\mathrm{P}$, $55 \mathrm{mg} / \mathrm{kg} ; \mathrm{Ca}^{2+}, 4,3 \mathrm{cmol}_{\mathrm{c}} / \mathrm{dm}^{3} ; \mathrm{Mg}^{2+}, 2,1 \mathrm{cmol}_{\mathrm{c}} / \mathrm{dm}^{3} ; \mathrm{K}^{+}$, $0,35 \mathrm{cmol}_{\mathrm{c}} / \mathrm{dm}^{3} ; \mathrm{Al}^{3+}, 0,0 \mathrm{cmol}_{\mathrm{c}} / \mathrm{dm}^{3}$. O plantio foi feito em 24 de agosto de 1993. As capinas foram realizadas 31 e 50 dias após o plantio, e as pulverizações com inseticida, 17 e 30 dias após o plantio.

Os dados foram submetidos a análises de variância individuais e conjunta, conforme Pimentel-Gomes (1990) e as médias comparadas pelo teste de Tukey a 5\% de probabilidade.

\section{Resultados e Discussão}

Não houve efeito, nas variáveis estudadas, da interação anos x tratamentos, e portanto, serão comparados apenas os efeitos principais dos dois fatores. Apesar disso, as diferenças entre alguns fatores climáticos (Tabela 1) afetaram o comportamento da cultura quanto a algumas características. Assim, as alturas da planta e de inserção da primeira espiga foram influenciadas significativamente pelo parcelamento do $\mathrm{N}$ e pelo ano de plantio (Tabela 2). As maiores alturas da planta foram obtidas com os tratamentos $0-1 / 2-1 / 2,1 / 3-2 / 3-0,0-2 / 3-1 / 3 \mathrm{e}$ $1 / 3-1 / 3-1 / 3$, e as menores, com o tratamento $0-0-1$. O tratamento $0-1 / 2-1 / 2$ propiciou plantas com maior altura de inserção da espiga, e os tratamentos
$1-0-0,0-0-1,1 / 2-0-1 / 2$ e $1 / 3-0-2 / 3$ determinaram menores alturas de inserção da espiga (Tabela 3 ). Portanto, a aplicação de, pelo menos, parte do N por ocasião do plantio ou aos 25 dias após o plantio parece ser importante para maior crescimento das plantas, pois o único tratamento que determinou menores plantas foi aquele no qual o $\mathrm{N}$ foi aplicado de uma só vez, aos 45 dias após o plantio (0-0-1). No caso da altura de inserção da espiga, a aplicação de, pelo menos, parte do $\mathrm{N}$ aos 25 dias após o plantio foi importante para a obtenção de maiores valores, pois dos cinco tratamentos nos quais o $\mathrm{N}$ não foi aplicado nesta época, apenas um (2/3-0-1/3) determinou altura de inserção da espiga que não diferiu das obtidas nos tratamentos que propiciaram maiores médias. Na média, as maiores alturas de planta e de inserção da espiga foram obtidas em 1992. Apesar dos efeitos dos tratamentos sobre as alturas da planta e de inserção da espiga, não se verificou acamamento de plantas tratadas diferentemente. Apesar de as alturas da planta e de inserção da espiga terem sido alteradas pelo parcelamento do $\mathrm{N}$, isto em nada alterou os procedimentos de colheita, feita na região, em geral manualmente. Também não foram observadas diferenças entre tratamentos no que se refere à porcentagem de espigas doentes ou atacadas por pragas, que, aliás, não ocorreram. Esechie et al. (1995), ao contrário do observado neste trabalho, não constataram efeitos de diferentes formas de parcelamento sobre a altura da planta, diâmetro basal do caule e número de folhas por planta.

Também houve efeito de parcelamento e de anos sobre o número de ramificações do pendão (Tabela 2). Os maiores pendões foram produzidos por plantas que receberam os tratamentos $1-0-0,1 / 2-1 / 2-0$ e $0-1 / 2-1 / 2$, e os menores, pelas plantas que recebe-

Tabela 2. Resumo da análise de variância conjunta dos dados das alturas da planta e de inserção da espiga e do número de ramificações do pendão da cultivar de milho Centralmex, em dois anos, em razão de épocas de aplicação de $120 \mathrm{~kg} / \mathrm{ha}$ de nitrogênio.

\begin{tabular}{lcccc}
\hline Fontes de variação & Graus de & \multicolumn{3}{c}{ Quadrados médios } \\
\cline { 3 - 5 } & liberdade & Altura da planta & Altura da espiga & № de ram./pendão \\
\hline Blocos/experimento & 6 & 679,2 & 248,4 & 5,6 \\
Épocas de aplicacação (E) & 12 & $514,5^{*}$ & $366,9^{*}$ & $13,1^{*}$ \\
Anos (A) & 1 & $13.030,1^{* *}$ & $3.299,6^{* *}$ & $134,3^{* *}$ \\
E x A & 12 & $113,0^{\mathrm{ns}}$ & $61,6^{\mathrm{ns}}$ & $3,6^{\mathrm{ns}}$ \\
Resíduo & 72 & 172,2 & 131,0 & 5,3 \\
\hline CV $(\%)$ & & 7 & 10 & 13 \\
\hline
\end{tabular}

ns Não-significativo. * e **Significativo a $5 \%$ e a $1 \%$ de probabilidade, respectivamente, pelo teste $\mathrm{F}$. 
ram todo o $\mathrm{N}$ aos 45 dias após o plantio (Tabela 4). Aparentemente, pendões menores são desejáveis por reduzirem a competição por fotossintatos entre espiga e pendão, devida à dominância apical (Leonard \& Kiesselbach, 1932; Chinwuba et al., 1961; Grogan, 1965).

Em relação ao rendimento de grãos, houve efeito apenas do parcelamento de $\mathrm{N}$ (Tabela 5). O maior rendimento foi obtido no tratamento $0-1 / 3-2 / 3$, apesar de ele não ter diferido significativamente de outros tratamentos (Tabela 6). Novais et al. (1974), Fox et al. (1986) e Melgar et al. (1991) também constataram vantagem do parcelamento do $\mathrm{N}$ em relação a sua aplicação de uma só vez. Apesar disso, existem divergências entre pesquisadores

Tabela 3. Médias de altura de planta $(\mathrm{cm})$ e de inserção da espiga $(\mathrm{cm})$ da cultivar de milho Centralmex, em razão de épocas de aplicação de $120 \mathrm{~kg} / \mathrm{ha}$ de $\mathrm{N}$, em dois anos ${ }^{(1)}$.

\begin{tabular}{|c|c|c|c|c|c|c|c|c|}
\hline \multirow{2}{*}{\multicolumn{3}{|c|}{$\begin{array}{c}\text { Tratamentos }^{(2)} \\
\text { Dias após a semeadura }\end{array}$}} & \multicolumn{3}{|c|}{ Altura da planta } & \multicolumn{3}{|c|}{ Altura da espiga } \\
\hline & & & \multicolumn{2}{|c|}{ Anos } & \multirow[t]{2}{*}{ Média } & \multicolumn{2}{|c|}{ Anos } & \multirow[t]{2}{*}{ Média } \\
\hline 0 & 25 & 45 & 1992 & 1993 & & 1992 & 1993 & \\
\hline $1(120)$ & 0 & 0 & 199 & 169 & $185 \mathrm{ab}$ & 118 & 95 & $107 b$ \\
\hline 0 & $1(120)$ & 0 & 206 & 176 & $191 \mathrm{ab}$ & 114 & 105 & $110 \mathrm{ab}$ \\
\hline 0 & 0 & $1(120)$ & 191 & 156 & $174 b$ & 105 & 86 & $96 b$ \\
\hline $1 / 2(60)$ & $1 / 2(60)$ & 0 & 203 & 187 & $195 \mathrm{ab}$ & 121 & 111 & $116 a b$ \\
\hline $1 / 2(60)$ & 0 & $1 / 2(60)$ & 192 & 174 & $183 \mathrm{ab}$ & 105 & 97 & $102 b$ \\
\hline 0 & $1 / 2(60)$ & $1 / 2(60)$ & 202 & 190 & $196 a$ & 121 & 114 & $118 \mathrm{a}$ \\
\hline $1 / 3(40)$ & $2 / 3(80)$ & 0 & 210 & 186 & $198 \mathrm{a}$ & 121 & 113 & $117 \mathrm{ab}$ \\
\hline $1 / 3(40)$ & 0 & $2 / 3(80)$ & 187 & 169 & $178 \mathrm{ab}$ & 107 & 97 & $102 b$ \\
\hline 0 & $1 / 3(40)$ & $2 / 3(80)$ & 206 & 182 & $195 \mathrm{ab}$ & 116 & 105 & $110 \mathrm{ab}$ \\
\hline $2 / 3(80)$ & $1 / 3(40)$ & 0 & 197 & 186 & $192 \mathrm{ab}$ & 117 & 114 & $115 \mathrm{ab}$ \\
\hline $2 / 3(80)$ & 0 & $1 / 3(40)$ & 209 & 179 & $194 a b$ & 119 & 104 & $112 \mathrm{ab}$ \\
\hline 0 & $2 / 3(80)$ & $1 / 3(40)$ & 210 & 183 & $197 a$ & 121 & 105 & $113 \mathrm{ab}$ \\
\hline $1 / 3(40)$ & $1 / 3(40)$ & $1 / 3(40)$ & 208 & 189 & $199 a$ & 116 & 110 & $113 \mathrm{ab}$ \\
\hline Média & & & $202 \mathrm{~A}$ & 179B & & $116 \mathrm{~A}$ & 104B & \\
\hline
\end{tabular}

(1)Para cada característica, médias seguidas pela mesma letra, minúscula na coluna e maiúscula na linha, não diferem entre si, a 5\% de probabilidade, pelo teste de Tukey. ${ }^{(2)} \mathrm{Aos} 25$ e 45 dias após a semeadura o $\mathrm{N}$ foi aplicado em cobertura; números entre parênteses indicam kg/ha de nitrogênio.

Tabela 4. Médias do número de ramificações do pendão da cultivar de milho Centralmex, em razão de épocas de aplicação de $120 \mathrm{~kg} / \mathrm{ha}$ de $\mathrm{N}$, em dois $\operatorname{anos}^{(1)}$.

\begin{tabular}{|c|c|c|c|c|c|}
\hline \multicolumn{3}{|c|}{ Tratamentos ${ }^{(2)}$} & \multicolumn{2}{|c|}{ Anos } & \multirow[t]{3}{*}{ Média } \\
\hline \multicolumn{3}{|c|}{ Dias após a semeadura } & \multirow{2}{*}{1992} & \multirow{2}{*}{1993} & \\
\hline 0 & 25 & 45 & & & \\
\hline $1(120)$ & 0 & 0 & 21,5 & 17,7 & $19,6 a$ \\
\hline 0 & $1(120)$ & 0 & 18,7 & 17,5 & $18,1 \mathrm{ab}$ \\
\hline 0 & 0 & $1(120)$ & 14,7 & 14,5 & $14,6 b$ \\
\hline $1 / 2(60)$ & $1 / 2(60)$ & 0 & 20,5 & 17,0 & $18,7 \mathrm{a}$ \\
\hline $1 / 2(60)$ & 0 & $1 / 2(60)$ & 18,8 & 14,5 & $16,6 \mathrm{ab}$ \\
\hline 0 & $1 / 2(60)$ & $1 / 2(60)$ & 18,7 & 18,5 & $18,6 a$ \\
\hline $1 / 3(40)$ & $2 / 3(80)$ & 0 & 19,7 & 17,0 & $18,4 \mathrm{ab}$ \\
\hline $1 / 3(40)$ & 0 & $2 / 3(80)$ & 18,2 & 14,5 & $16,3 \mathrm{ab}$ \\
\hline 0 & $1 / 3(40)$ & $2 / 3(80)$ & 18,4 & 17,5 & $18,0 \mathrm{ab}$ \\
\hline $2 / 3(80)$ & $1 / 3(40)$ & 0 & 19,2 & 17,0 & $18,1 \mathrm{ab}$ \\
\hline $2 / 3(80)$ & 0 & $1 / 3(40)$ & 18,1 & 16,3 & $17,2 \mathrm{ab}$ \\
\hline 0 & $2 / 3(80)$ & $1 / 3(40)$ & 20,0 & 16,8 & $18,2 \mathrm{ab}$ \\
\hline $1 / 3(40)$ & $1 / 3(40)$ & $1 / 3(40)$ & 19,0 & 16,8 & $17,9 \mathrm{ab}$ \\
\hline Média & & & $18,9 \mathrm{~A}$ & $16,6 \mathrm{~B}$ & \\
\hline
\end{tabular}

(1)Para cada característica, médias seguidas pela mesma letra, minúscula na coluna e maiúscula na linha, não diferem entre si, pelo teste de Tukey, a 5\% de probabilidade. ${ }^{(2)}$ Aos 25 e 45 dias após a semeadura o $\mathrm{N}$ foi aplicado em cobertura; números entre parênteses indicam kg/ha de nitrogênio. 
quanto à época do parcelamento. Assim, Esechie et al. (1995) verificaram que o parcelamento 1/3 (plantio)-2/3 (42 dias após o plantio)-0 (63 dias após o plantio) foi superior aos parcelamentos $1 / 3-0-2 / 3$ e 1/3-1/3-1/3. Por outro lado, Novais et al. (1974) verificaram que a aplicação parcelada do $\mathrm{N}-1 / 3$ no plantio e $2 / 3$ aos 45 dias - e da dose total 45 dias depois do plantio foram os melhores tratamentos para a produção de espigas. No presente trabalho, embora o tratamento $0-1 / 3-2 / 3$, que propiciou o maior rendimento, não tenha diferido de tratamentos nos quais o $\mathrm{N}$ foi aplicado de uma só vez, aos 25 ou 45 dias após o plantio, as diferenças entre rendimentos foram relativamente elevadas $(958 \mathrm{~kg} / \mathrm{ha} \mathrm{e}$ $495 \mathrm{~kg} / \mathrm{ha}$, respectivamente). Os piores rendimentos foram obtidos quando se aplicou a totalidade ou a maior parte do $\mathrm{N}$ por ocasião do plantio (Tabela 6). Melgar et al. (1991) também verificaram que o menor rendimento de grãos foi obtido quando o $\mathrm{N}$ foi aplicado de uma só vez, por ocasião do plantio, em doses que variaram de 40 a $120 \mathrm{~kg} / \mathrm{ha}$ de nitrogênio. Walther (1995) também obteve maiores rendimentos com aplicação mais tardia do nitrogênio.

O maior rendimento com o tratamento $0-1 / 3-2 / 3$ talvez tenha como causa o fato de que, quando aplicado tardiamente, o $\mathrm{N}$ é fornecido à planta na época em que sua absorção é máxima, ou seja, duas a três semanas antes da floração (Russelle et al., 1983), apesar de a absorção do $\mathrm{N}$ pelo milho continuar até próximo à maturidade (Hanway, 1971). A cultivar Centralmex utilizada no presente trabalho floresce, na região, em torno de 60 a 65 dias após o plantio, isto é, aproximadamente três semanas após a última aplicação (45 dias após o plantio). Andrade (1975), avaliando a extração e exportação de macro e micronutrientes por cinco cultivares de milho, dentre as quais a cultivar Centralmex, verificou que o $\mathrm{N}$ foi acumulado na parte aérea da planta até os 80 dias após a germinação, decrescendo após esse período em razão de degenerescência e perda de partes vegetativas e de excreção pelo sistema radicular. A aplicação tardia limita ou reduz o potencial para perda do N por lixiviação ou desnitrificação, pois além do $\mathrm{N}$ permanecer no solo por um período menor de tempo, nessa ocasião já existe um sistema radicular ativo em crescimento, para absorção do $\mathrm{N}$ aplicado (Olson \& Kurtz, 1982). MacKay \& Barber (1986) atribuíram parcialmente a melhor resposta ao $\mathrm{N}$ do híbrido B73 x MO17, em termos de rendimento de grãos, a uma maior extensão do sistema radicular deste híbrido. Como no presente trabalho os experimentos foram realizados com irrigação, a água deve ter contribuído para perdas do nutriente, especialmente quando ele foi aplicado em grandes proporções por ocasião do plantio. O solo experimental, muito arenoso, mas de ocorrência generalizada na região é outro fator que pode ter contribuído para as perdas do referido nutriente. Finalmente, dentre outros fatores, deve ser mencionado que os valores do $\mathrm{pH}(6,4$ e 7,5), nos dois anos, devem ter contribuído para as perdas por lixiviação, pois segundo Paul \& Clark (1996), a faixa de pH ótima para nitrificação varia de 6,6 a 8,0 e, em geral, ela diminui abaixo de pH 6,0 e torna-se negligível abaixo de pH 4,5.

Tabela 5. Resumo da análise de variância conjunta dos dados de rendimento de grãos, número de espigas/ha, número de grãos/espiga e peso de 100 grãos da cultivar de milho Centralmex, em dois anos, em razão de épocas de aplicação de $120 \mathrm{~kg} / \mathrm{ha}$ de nitrogênio.

\begin{tabular}{lccccc}
\hline Fontes de variação & $\begin{array}{c}\text { Graus de } \\
\text { liberdade }\end{array}$ & \multicolumn{2}{c}{ Quadrados médios } \\
\cline { 3 - 6 } & & $\begin{array}{c}\text { Rendimento de } \\
\text { grãos }\end{array}$ & $\begin{array}{c}\text { No de } \\
\text { espigas/ha }\end{array}$ & $\begin{array}{c}\text { No de } \\
\text { grãos/espiga }\end{array}$ & $\begin{array}{c}\text { Peso de } 100 \\
\text { grãos }\end{array}$ \\
\hline Blocos/experimento & 6 & $4.125 .005,0$ & $200.980 .346,0$ & $9.243,7$ & 12,9 \\
Épocas de aplicação (E) & 12 & $5.106 .396,0^{* *}$ & $180.905 .452,0^{* *}$ & $8.212,2^{\text {ns }}$ & $15,3^{\text {ns }}$ \\
Anos (A) & 1 & $2.108 .431,0^{\text {ns }}$ & $333.383 .939,0^{* *}$ & $906,2^{\text {ns }}$ & $572,0^{* *}$ \\
Ex A & 12 & $1.125 .435,0^{\text {ns }}$ & $34.620 .466,0^{\text {ns }}$ & $4.601,3^{\text {ns }}$ & $10,0^{\text {ns }}$ \\
Resíduo & 72 & $779.929,0$ & $39.102 .042,0$ & $2.735,0$ & 9,8 \\
\hline CV $(\%)$ & & 23 & 15 & 16 & 10 \\
\hline
\end{tabular}

nsNão-significativo. **Significativo a $1 \%$ de probabilidade pelo teste $\mathrm{F}$. 


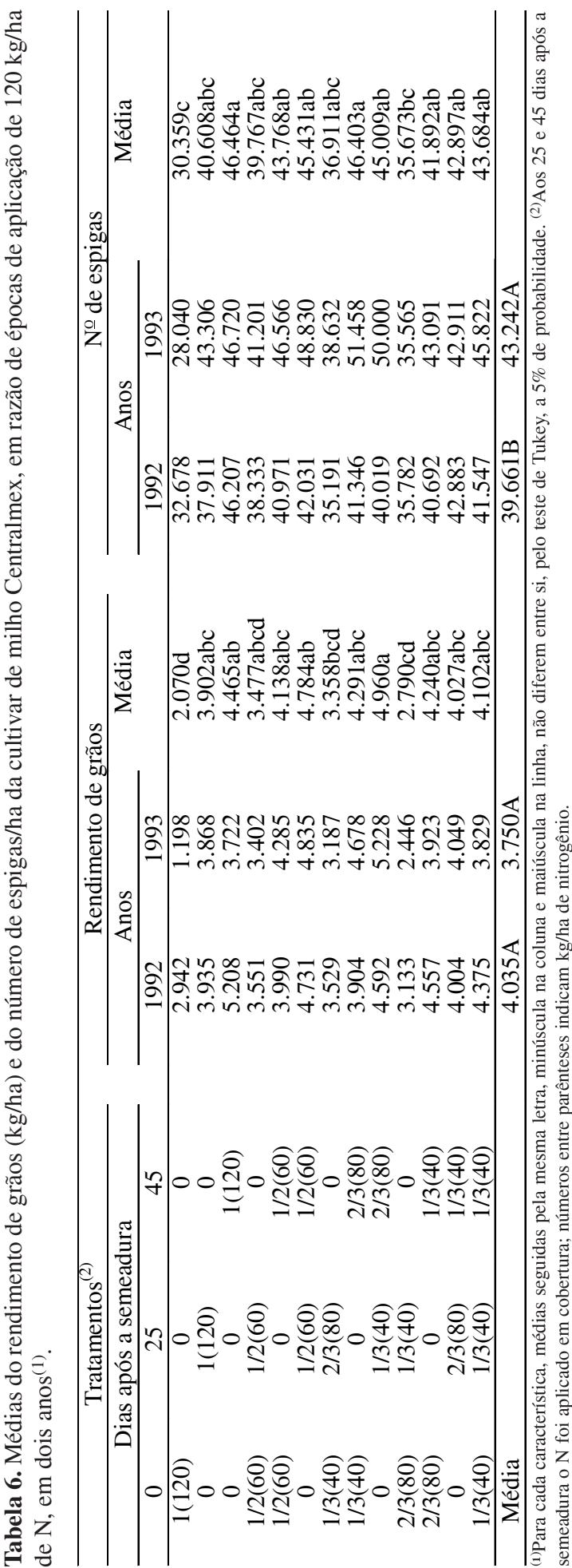

Reichardt et al. (1982) concluíram que perdas por lixiviação não constituem problema, com aplicações da ordem de $90 \mathrm{~kg} / \mathrm{ha}$ de N. De fato, segundo Yamada \& Abdalla (2000), as principais perdas de $\mathrm{N}$ ocorrem na forma de gases, que são liberados na atmosfera, pela volatilização da amônia e por desnitrificação, realizada por bactérias encontradas no solo, e por imobilização biológica. Segundo eles, as perdas por volatilização seriam evitadas pela incorporação da uréia em profundidade no solo, misturando-se uréia e cloreto de potássio na forma líquida ou misturando-se uréia e sulfato de amônio.

Houve efeito de anos e de tratamentos no número de espigas/ha (Tabela 5); o maior número de espigas foi produzido em 1992 nos tratamentos 0-0-1 e $1 / 3-0-2 / 3$, os quais foram significativamente superiores aos dos tratamentos $1-0-0$ e $2 / 3-1 / 3-0$ (Tabela 6).

Houve efeito de tratamentos no número de grãos/ espiga (Tabela 5). Os tratamentos $0-0-1,1 / 3-0-2 / 3$, $0-1 / 3-2 / 3,2 / 3-0-1 / 3,0-2 / 3-1 / 3$ e $1 / 3-1 / 3-1 / 3$ foram os que propiciaram maiores números de grãos/ espiga e diferiram apenas do tratamento 1-0-0 (Tabela 7).

Não houve efeito de tratamentos sobre o peso de 100 grãos (Tabela 5), apesar de esta característica ter variado de 28,9 g a 33,1 g. Contudo, em 1993 foram produzidos grãos mais pesados que em 1992 (Tabela 7).

Os resultados obtidos por Ahmed (1989) com relação aos componentes do rendimento de grãos concordam, de certa forma, com os resultados apresentados nas Tabelas 6 e 7, ou seja, o número de espigas/planta, o número de fileiras de grãos/espiga e o número de grãos/fileira de grãos foram reduzidos quando a proporção do $\mathrm{N}$ aplicado por ocasião do plantio aumentou de $0 \%$ para $30 \%$.

A aplicação do $\mathrm{N}$, de uma só vez ou parceladamente, pode ser mais ou menos eficiente, dependendo da época em que ele é aplicado (Tabelas 2, 4, 6 e 7). No caso do rendimento de grãos, por exemplo, a aplicação de todo o $\mathrm{N}$ aos 25 ou 45 dias após o plantio diferiu significativamente da aplicação por ocasião do plantio (Tabela 6). Quando o N foi dividido em $1 / 3$ e $2 / 3$, o tratamento $0-1 / 3-2 / 3$ foi superior ao tratamento1/3-2/3-0. A aplicação parcelada ou de todo o $\mathrm{N}$ pode ter outras implicações práti- 


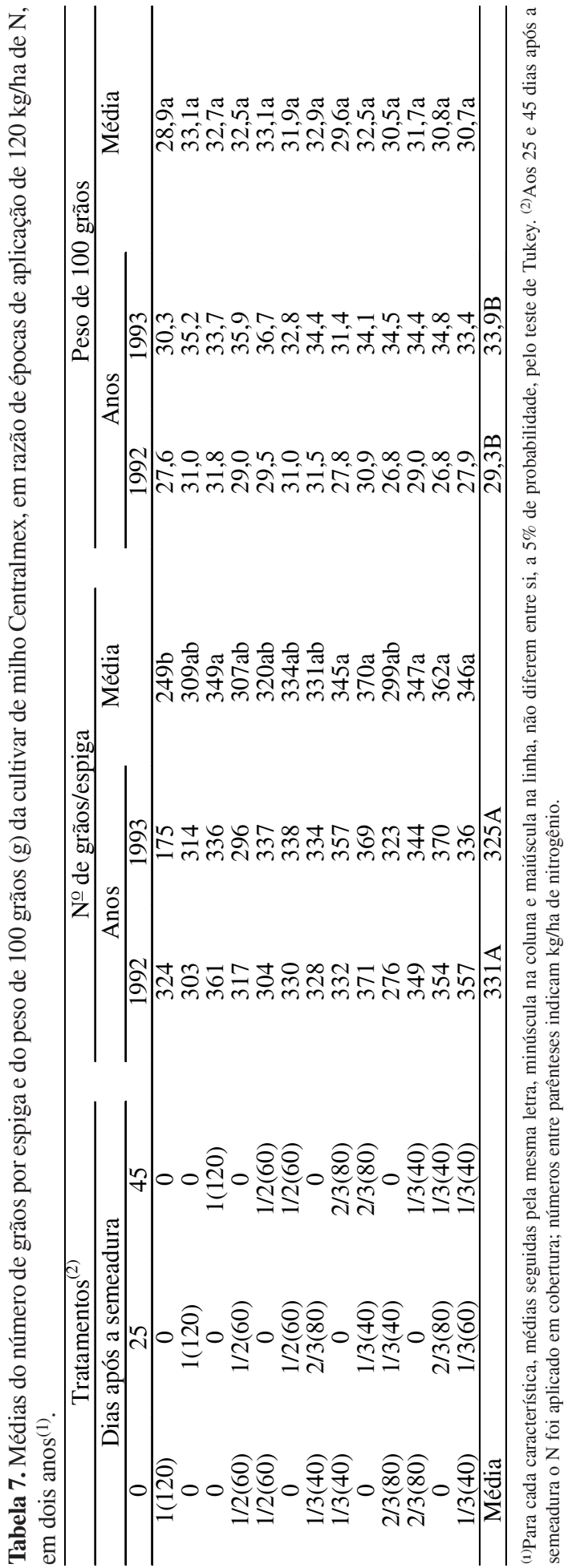

cas, além das relacionadas com maiores rendimentos. Por exemplo, a aplicação parcelada implicaria maiores gastos que a aplicação feita de uma só vez. Mas a diferença média de $495 \mathrm{~kg} / \mathrm{ha}$ obtida, em comparação com os tratamentos que propiciaram rendimentos máximos (médias de dois anos) com a aplicação parcelada e aplicação do fertilizante de uma só vez, isto é, 0-1/3-2/3 (4.960 kg/ha) e 0-0-1 (4.465 kg/ha), deve compensar o custo adicional com mais uma adubação em cobertura. Outro aspecto é que as adubações manuais em cobertura mais tardias, quando as plantas já estão maiores são mais trabalhosas.

\section{Conclusões}

1. Os efeitos das épocas de aplicação do N sobre as características avaliadas são independentes do ano de avaliação.

2. O ano experimental não influencia o rendimento de grãos, mas influencia as alturas da planta e de inserção da espiga, o número de ramificações do pendão, o número de espigas/ha e o peso de 100 grãos.

3. A aplicação do N, de uma só vez ou parceladamente tem efeitos diferentes, dependendo da época em que o nutriente é aplicado.

4. Maior rendimento de grãos é obtido com o tratamento $0-1 / 3-2 / 3$, mas todos os outros tratamentos proporcionam rendimentos equivalentes, exceto os tratamentos 1-0-0, 1/3-2/3-0 e 2/3-1/3-0, que propiciam os menores rendimentos.

\section{Referências}

AHMED, M. A. Effect of nitrogen fertilizer levels and time of nitrogen application on yield and its components of maize in Egypt. Egyptian Journal of Agronomy, Cairo, v. 14, p. 103-115, 1989.

ANDRADE, A. G. Acumulação diferencial de nutrientes por cinco cultivares de milho (Zea mays L.). 1975. 75 f. Dissertação (Mestrado) - Escola Superior de Agricultura Luiz de Queiroz, Piracicaba.

BAIR, W.; McGAHEN, J. H.; AYERS, J. E. Effect of time and rate of $\mathrm{N}$ side-dress application on Northern corn leaf blight severity and the associated yield loss. Journal of Production Agriculture, Madison, v. 3, p. 44-49, 1990. 
BONDAVALLI, B.; COLYER, D.; KROTH, E. M. Effects of weather, nitrogen and population on corn yield response. Agronomy Journal, Madison, v. 62, p. 669-672, 1970.

CARDWELL, V. B. Fifty years of Minnesota corn production: sources of yield increase. Agronomy Journal, Madison, v. 74, p. 984-990, 1982.

CARLONE, M. R.; RUSSELL, W. A. Response to plant densities and nitrogen levels for four maize cultivars from different eras of breeding. Crop Science, Madison, v. 27, p. 465-470, 1987.

CHINWUBA, P. M.; GROGAN, C. O.; ZUBER, M. S. Interaction of detasseling, sterility and spacing of maize hybrids. Crop Science, Madison, v. 1, p. 279-280, 1961.

ESECHIE, H. A.; ELIAS, S.; MAGPANTAY, Y. Timing of nitrogen application to enhance corn (Zea mays L.) in a desert climate. Journal of Agronomy and Crop Science, Berlin, v. 175, p. 271-278, 1995.

FOX, R. H.; KERN, J. M.; PIEKIELEK, W. P. Nitrogen fertilizer source, and method and time of application effects on non-till corn yields and nitrogen uptake. Agronomy Journal, Madison, v. 78, p. 741-746, 1986.

GROGAN, C. O. Detasseling responses in corn. Agronomy Journal, Madison, v. 48, p. 247-249, 1965.

HANWAY, J. J. How a corn plant develops. Ames: Iowa State University, 1971. 48 p.

LEONARD, R. B.; KIESSELBACH, T. A. The effect of the removal of tassels on the yield of corn. Agronomy Journal, Madison, v. 24, p. 514-516, 1932.

MacKAY, A. D.; BARBER, S. A. Effect of nitrogen on root growth of two corn genotypes in the field. Agronomy Journal, Madison, v. 78, p. 699-703, 1986.

MELGAR, R. J.; SMYTH, T. J.; CRAVO, M. S. Aplicação de fertilizante nitrogenado para milho em Latossolo da Amazônia. Revista Brasileira de Ciência do Solo, Campinas, v. 15, p. 289-296, 1991.

MELO, W. M. C.; PINHO, R. G. V.; PINHO, E. V. de R. V.; CARVALHO, M. L. M. de; FONSECA, A. H. Parcelamento da adubação nitrogenada sobre o desempenho de cultivares de milho para produção de forragem.
Ciência e Agrotecnologia, Lavras, v. 23, p. 608-616, 1999.

NOVAIS, M. V. de; NOVAIS, R. F.; BRAGA, J. M. Efeito da adubação nitrogenada e de seu parcelamento sobre a cultura do milho, em Patos de Minas. Revista Ceres, Viçosa, MG, v. 21, p. 193-202, 1974.

OLSON, R. A.; KURTZ, L. T. Crop nitrogen requirements, utilization and fertilization. In: STEVENSON, F. J. (Ed.). Nitrogen in agricultural soils. Madison: American Society of Agronomy, 1982. p. 567-604. (ASA Monograph, 22).

PAUL, E. A.; CLARK, F. E. Soil microbiology and biochemistry. San Diego: Academic, 1996. 345 p.

PIMENTEL-GOMES, F. Estatística experimental. 13. ed. Piracicaba: Nobel, 1990. 232 p.

REEVES, D. W.; WOOD, C. W.; TOUCHTON, J. T. Timing nitrogen applications for corn in a winter legume conservation-tillage system. Agronomy Journal, Madison, v. 85, p. 98-106, 1993.

REICHARDT, K.; LIBARDI, P. L.; CABALLERO URQUIAGA, S. S. Fate of fertilizer nitrogen in soil-plant systems with emphasis on the tropics. In: INTERNATIONAL ATOMIC ENERGY AGENCY (Vienna, Austria). Agrochemicals: fate in food and the environment. Vienna, 1982. p. 277-290.

RUSSELlE, M. P.; HAUCK, R. D.; OLSON, R. A. Nitrogen accumulation rates of irrigated maize. Agronomy Journal, Madison, v. 75, p. 593-598, 1983.

WALTHER, U. Stickstoffdüngung zu Mais - zur Saat oder später. Agrarforschung, Posieux, v. 2, p. 129-132, 1995.

YAMADA, T.; ABDALLA, S. R. S. e. Como melhorar a eficiência da adubação nitrogenada do milho? Informações Agronômicas, Piracicaba, n. 91, p. 1-5, set. 2000.

ZIZKA, J.; ISFAN, D. Effet des sources, des méthodes d'application et du fractionnement de l'azote chez le maïs fourrager. Naturaliste Canadien, Québec, v. 117, p. 183-188, 1993. 